\title{
BMJ Open Is researching adverse events in hospital deaths a good way to describe patient safety in hospitals: a retrospective patient record review study
}

\author{
Rebecca J Baines, ${ }^{1}$ Maaike Langelaan, ${ }^{2}$ Martine C de Bruijne,${ }^{1}$ Cordula Wagner ${ }^{1,2}$
}

To cite: Baines RJ, Langelaan M, de Bruijne MC, et al. Is researching adverse events in hospital deaths a good way to describe patient safety in hospitals: a retrospective patient record review study. BMJ Open 2015;5:e007380.

doi:10.1136/bmjopen-2014007380

- Prepublication history for this paper is available online. To view these files please visit the journal online (http://dx.doi.org/10.1136/ bmjopen-2014-007380).

Received 4 December 2014 Revised 28 March 2015 Accepted 23 April 2015

\section{(1) corssatax}

${ }^{1}$ NIVEL, Netherlands Institute for Health Services Research, Utrecht, The Netherlands ${ }^{2}$ Department of Public and Occupational Health, VU University Medical Center (VUmc), EMGO Institute for Health and Care Research, Amsterdam, The Netherlands

Correspondence to Dr Rebecca J Baines; r.baines@vumc.nl

\section{ABSTRACT}

Objective: Adverse event studies often use patient record review as a way to assess patient safety. As this is a time-consuming method, hospitals often study inpatient deaths. In this article we will assess whether this offers a representative view of the occurrence of adverse events in comparison to patients who are discharged while still living.

Design: Retrospective patient record review study. Setting and participants: A total of 11949 hospital admissions; $50 \%$ of inpatient deaths; the other half of patients discharged while alive. The data originated from our two national adverse event studies in 2004 and 2008.

Main outcome measures: Overall adverse events and preventable adverse events in inpatient deaths, and in admissions of patients discharged alive. We looked at size, preventability, clinical process and type of adverse events.

Results: Patients who died in hospital were on an average older, had a longer length of stay, were more often urgently admitted and were less often admitted to a surgical unit. We found twice as many adverse events and preventable adverse events in inpatient deaths than in patients discharged alive. Consistent with the differences in patient characteristics, preventable adverse events in inpatient deaths were proportionally less and were often related to the surgical process. Most types of adverse events and preventable adverse events occur in inpatient deaths as well as in patients discharged alive; however, these occur more often in inpatient deaths and are differently distributed.

Conclusions: Reviewing patient records of inpatient deaths is more efficient in identifying preventable AEs than reviewing records of those discharged alive. Although many of the same types of adverse events are found, it does not offer a representative view of the number or type of adverse events.

\section{INTRODUCTION}

Retrospective patient record review is a commonly used method for estimating national incidences, nature and preventability of adverse events (AEs). ${ }^{1-5}$ These studies have

\section{Strengths and limitations of this study}

- This study consists of a large representative sample of nearly 12000 patient admissions, consisting of $50 \%$ inpatient deaths and $50 \%$ patient admissions discharged alive.

- To our knowledge, no previous study has compared inpatient deaths and hospital admissions discharged alive for number and type of adverse events (AEs).

- To acquire information on as many improvement possibilities as possible, studying inpatient deaths seems to be an efficient manner to identify preventable AEs.

- It is important to be aware that when studying only inpatient deaths, some problems remain underexposed or unexposed, especially when using the results to prioritise improvement possibilities.

- Limitations of this study can be seen in the standard limitations of retrospective patient record review studies, such as information bias, moderate reliability and hindsight bias. However, these are not likely to have a large effect on the results of the distribution of type of AEs.

led to an increased sense of urgency to improve patient safety and to global directions for hospital safety improvement programmes.

A number of studies have partly or specifically focused on inpatient deaths, to estimate the relationship between an $\mathrm{AE}$ and death. $^{2}{ }^{6-8}$ These studies report considerable numbers of preventable deaths due to hospital care. Previous studies from our group have also shown higher risks of experiencing preventable AEs in this specific subgroup. ${ }^{29}$ This means that through studying inpatient deaths, not only is information on the most serious outcomes of AEs acquired, but also more indications can be found as to where improvements are possible. 
One method will not identify all types of patient safety issues. ${ }^{10-12}$ Retrospective patient record review seems especially useful as a means to assess whether negative patient outcomes are brought on by healthcare or healthcare management. However, it does have certain limitations in, for example, analysis of causes or insight into deviations in processes as captured by incident reports. Despite the downsides, retrospective patient record review does provide the best characterisation of the overall rate of harm at a given time. ${ }^{13}$ It is, however, also a very time-consuming and costly method, and from this point of view efficiency is welcome. In totality, studying inpatient deaths through $\mathrm{AE}$ research instigates a sense of urgency which is more than that from studying the total hospital population because of the serious outcome of preventable deaths. However, inpatient deaths are a relatively small proportion of inpatient admissions; in the Netherlands, inpatient deaths in 2008 made up around $3 \%$ of the total inpatient admissions (source: Dutch Hospital Data). So the question arises as to whether the same type of patient safety lessons can be learnt from studying inpatient deaths as from studying admissions of patients who are discharged alive with a two-stage review process.

For substantiation of previous research and to direct future research, as well to inform hospitals doing their own research on hospital deaths, it is important to know whether studying inpatient deaths is efficient and offers a representative view of the number and type of AEs in hospitals in comparison to patients who are discharged alive.

\section{METHODS}

\section{Study design and population}

We used the data from our two previous AE studies. ${ }^{2} 9$ In the Netherlands, we performed AE studies with patient records from 2004 to 2008 to estimate national incidences of AEs and preventable AEs. In both measurements, half of the patient admissions were of inpatient deaths and the other half of admitted patients discharged alive, making it an ideal sample to compare the two groups. The hospital samples were stratified for hospital type: university, tertiary teaching and general hospitals. Within these strata, the hospitals were randomly selected and a proper representation of urban and rural settings in the samples was verified. For the 2004 measurement, 21 hospitals were included, and 20 hospitals for the 2008 measurement. Within the hospitals, half of the sample consisted of patient admissions who were discharged alive from the hospital after a stay of at least $24 \mathrm{~h}$; the other half were inpatient deaths regardless of the length of stay. Within these strata, patient admissions were randomly selected. Patients admitted with an explicit palliative care plan were not excluded, and this information was taken into account during the review process. As is also common in other $\mathrm{AE}$ studies, the psychiatry department, obstetrics admissions and children younger than 1 year were excluded. For the 2004 measurement, in each hospital, 400 randomly chosen patient admissions were reviewed, and 200 patient admissions for the 2008 measurement. In all hospitals, $50 \%$ of patient records were from inpatient deaths and the other $50 \%$ from patient admissions discharged alive.

\section{Patient record review}

Trained external nurses and external physicians reviewed the nursing, medical, and-if available-outpatient records. The method of determining AEs was the same in both groups, and comparable to those of other international studies and based on the Canadian AE study. ${ }^{3}$ First a nurse screened the records by using triggers indicating potential AEs. One trigger did not apply for deceased patients: "readmission within 12 months after discharge of the index admission". Admissions positive for at least one trigger were further reviewed by a physician. The physicians belonged to the surgery, internal medicine or neurology specialties, and, if needed, could consult with specialties other than their own. Patient records of the index hospital admission were reviewed, as were the patient records of patient admissions a year before and a year after the index admission. Presence and preventability of an $\mathrm{AE}$ was determined for all patients based on a standardised procedure and preceded by a number of underlying questions to secure a systematic assessment. ${ }^{9}$ In addition, for the patients who died in hospital, the physician reviewers also assessed whether the preventable AEs had specifically contributed to the patients' death, leading to potentially preventable death.

\section{Assessing AEs}

An $\mathrm{AE}$ was defined by three criteria:

1. An unintended injury

2. Resulting in prolongation of hospital stay, temporary or permanent disability or death

3. Caused by healthcare management rather than the patient's disease.

An $\mathrm{AE}$ was found to be preventable when the care given was not in compliance with existing professional standards and/or due to shortcomings of a healthcare practitioner, management or system. A six-point Likert scale was used to score the likelihood of cause by healthcare management as well as the preventability. A score of 4-6 indicated that the reviewer regarded the event as having a greater than $50 \%$ chance of being caused by healthcare or being preventable. If a preventable $\mathrm{AE}$ had occurred in a deceased patient, the physicians also assessed whether the preventable $\mathrm{AE}$ had contributed to the death of that patient. If this was the case, it was marked as a potentially preventable death; 'potentially' because of the multifactorial nature of hospital deaths and the retrospective assessment of the causality. With regard to the timing of AEs, AEs that occurred during the patient's index hospital admission and those that 
were detected during either the index admission or subsequent admissions over the following 12-month period were counted. Also counted were AEs related to patient admissions in the same hospital within the 12 months preceding the index admission but which were not detected until the index admission. If an $\mathrm{AE}$ was identified, questions about the clinical process during which the AE occurred were asked, and physicians were able to choose from the following clinical processes: diagnostics: being an incorrect diagnosis or a diagnosis made too late; surgery: during the surgery or within a 30-day postoperative period; drug/fluid; medical procedure; other clinical management, including care given by nurses; discharge and others.

The review process of the 2004 study was slightly modified for the 2008 study. In short, in the 2004 study, pairs of physicians independently assessed all records positive for screening criteria in the first stage review. Disagreement about the presence and/or preventability of an $\mathrm{AE}$ prompted a consensus procedure. ${ }^{14}$ In the 2008 study, all records positive for screening criteria were reviewed by one physician and standardisation of reviews was supported by regular meetings to discuss inter-rater differences based on double-blind reviews in $10 \%$ of all records. As we are not comparing the years, we do not feel this adaptation has a major influence on the results of this article. In 2004, between pairs of specialists for AEs, positive agreement was $54.9 \%$ and negative agreement $66.2 \%$. In 2008, for AEs positive agreement was $56.9 \%$ and negative agreement $82.9 \%$.

\section{Exploration of type of AEs}

Complementary to the analysis of AEs, preventability and related clinical processes, we also wanted to acquire more information on the specific types of AEs. We, therefore, classified the type of $\mathrm{AE}$ or preventable $\mathrm{AE}$ into more specific subgroups. We based our classification on the classification used by Landrigan $e t a l^{15}$ in their study. Based on the information in the structured review and description of the $\mathrm{AE}$, one researcher classified the AEs. In the cases where the researcher was unsure of the chosen classification, a second researcher also assessed the $\mathrm{AE}$ and the outcome was compared.

\section{Analysis}

The proportions of both samples, the sample of patients discharged alive and the sample of inpatient deaths, were weighted in the same manner for the different proportions of types of hospitals (university, tertiary teaching or general) in the sample in comparison to the total hospital population in our country. All proportions were weighted for the over-representation of university hospitals in the sample frame. After weighting, the estimates were representative of the total Dutch population of hospitalised patients, either discharged alive or inpatient deaths. The sample weight was the inverse of the probability of being included in the sample due to the sample design. All statistical analyses were performed in SPSS V.20.0.

Summary and descriptive statistics of patient characteristics of inpatient deaths and patients discharged alive were calculated.

Weighted rates of AEs and preventable AEs were calculated with 95\% CIs. Preventability of AEs, related clinical process and more specific types of AEs were assessed for both groups.

All differences between patients discharged alive and inpatient deaths, except for the more specific types of AEs due to small numbers, were tested using proportion tests for two independent groups, with corrections for the binomial distribution and continuity.

\section{RESULTS}

In total, 11949 of the 12400 sampled patient admissions were reviewed: 5990 inpatient deaths and 5959 patients discharged alive. The 451 patient records that were not reviewed were unavailable or inadequate for review.

AEs and preventable AEs were found more than twice as often in inpatient deaths than in the patients discharged alive (table 1). In all admissions, 1256 AEs were found in 1130 patients, and 855 AEs in 762 inpatient deaths, of which 375 were found to be preventable (weighted $46.5 \%$ ). In patients discharged alive, 401 AEs in 368 admissions were found, of which 146 were found to be preventable (weighted $37.7 \%$ ). Of the inpatient deaths, $5.8 \%$ (95\% CI $5.2 \%$ to $6.5 \%$ ) experienced a preventable $\mathrm{AE}$; in patients who were discharged alive this was $2.3 \%$ (95\% CI $1.9 \%$ to $2.7 \%$ ). In $4.5 \%$ (95\% CI $4.0 \%$ to $5.1 \%$ ) of the deceased patients, the AE contributed to the death of that patient (table 1).

Patient characteristics differed between inpatient deaths and patients discharged alive. Inpatient deaths were on average older, the largest group falling into the ' 80 years and older' category in contrast with patients discharged alive, who most often fell into the 41-65 years age group. Admission characteristics also differed: patients who died in hospital had on average a longer length of hospital stay and were more often urgently admitted. The department the patient was admitted to also differed between the two groups: inpatient deaths had more often been admitted to the intensive care unit or the internal medicine, neurology and lung disease departments, but less often admitted to a surgical department such as urology, orthopaedics, ear, nose and throat, and paediatrics (table 2).

We further assessed the clinical process related to preventable AEs in inpatient deaths and patient admissions discharged alive (figure 1). In inpatient deaths, $27.8 \%$ of the preventable AEs were related to diagnostics, as opposed to $12.9 \%$ of the patients discharged alive $(p<0.001)$. AEs and preventable AEs of patients discharged alive were proportionally more often related to surgery. In $53.7 \%$ of the preventable AEs, the related clinical process was surgery in patients discharged alive, 
Table 1 Rate of patients, either inpatient death or discharged alive, who experienced at least one adverse event (AE), preventable $\mathrm{AE}$ or preventable death

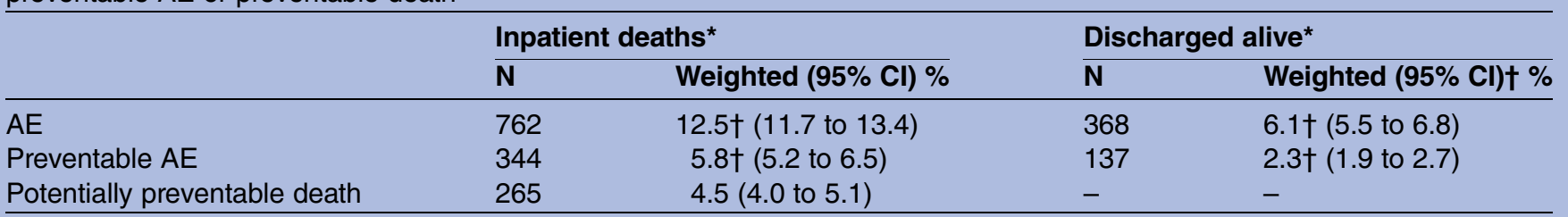

${ }^{*}$ For AEs, preventable AEs and preventable deaths unweighted numbers are given, \% are weighted for hospital type.

†Significant differences between inpatient deaths and patients discharged alive $(p<0.001)$.

as opposed to $29.7 \%$ of the inpatient deaths $(\mathrm{p}<0.001)$. This lower proportion of surgical preventable AEs in inpatient deaths is primarily related to fewer admissions to surgical departments in this group (table 2). When analysing the clinical process related to the preventable AEs for the subgroup of patients who were admitted to a surgical department, these differences disappear to a large extent. For inpatient deaths, $70.7 \%$ of the preventable AEs is then related to the surgical process while for patients discharged alive, this is $81.6 \%$.

Looking more closely into specific types of AEs and preventable AEs, two main differences stand out. First, all main types and almost all subtypes of AEs and preventable AEs occur in both groups, but more often in inpatient deaths than in patients discharged alive (table 3). The most pronounced examples of subtypes of AEs occurring more often in inpatients deaths are: heart failure (32 vs 4), pulmonary embolus (23 vs 4), haemorrhage (29 vs 12), ileus (14 vs 6 ), perforation (17 vs 3 ) and stroke or intracerebral haemorrhage (30 vs 4) (table 3 ). Some of these AEs were also found relatively often to be preventable in inpatient deaths; for example, $78 \%$ of the 23 pulmonary emboli and $71 \%$ of the 14 ileus were preventable. Some AEs are found more often in patients discharged alive:

Table 2 Descriptives of patient characteristics of the study sample, for inpatient deaths and patients discharged alive

\begin{tabular}{|c|c|c|c|c|c|}
\hline & \multicolumn{2}{|c|}{ Inpatient deaths* } & \multicolumn{2}{|c|}{ Discharged alive* } & \multirow[b]{2}{*}{ Significance } \\
\hline & $\mathbf{N}$ & Weighted \% & $\mathbf{N}$ & Weighted \% & \\
\hline Inpatient admissions & \multicolumn{2}{|l|}{5990} & \multicolumn{2}{|l|}{5959} & \\
\hline \multicolumn{6}{|l|}{ Patient admissions } \\
\hline University hospital & 1179 & 15.1 & 993 & 12.6 & $<0.001$ \\
\hline Tertiary teaching & 1748 & 33.3 & 1795 & 34.0 & 0.215 \\
\hline General† & 3063 & 51.6 & 3171 & 53.4 & 0.013 \\
\hline Male sex & 3217 & 53.7 & 2924 & 49.0 & $<0.001$ \\
\hline Age in years, mean (median/SD) & \multicolumn{2}{|c|}{$73.7(76.0 / 13.7)$} & \multicolumn{2}{|c|}{$57.4(61.0 / 21.3)$} & $<0.001$ \\
\hline \multicolumn{6}{|l|}{ Age categories } \\
\hline $1-18$ & 35 & 0.5 & 433 & 7.0 & $<0.001$ \\
\hline $19-40$ & 131 & 2.0 & 802 & 13.3 & $<0.001$ \\
\hline $41-65$ & 1264 & 20.7 & 2253 & 37.9 & $<0.001$ \\
\hline $66-79$ & 2238 & 37.3 & 1674 & 28.2 & $<0.001$ \\
\hline 80 and older & 2314 & 39.3 & 796 & 13.6 & $<0.001$ \\
\hline Length of hospital stay, days (median/SD) & \multicolumn{2}{|c|}{$12.0(7.0 / 15.3)$} & \multicolumn{2}{|c|}{$7.7(5.0 / 9.6)$} & $<0.001$ \\
\hline Urgent admission & 5172 & 87.0 & 3061 & 52.2 & $<0.001$ \\
\hline \multicolumn{6}{|l|}{ Department to which patient was admitted } \\
\hline Cardiology & 717 & 12.3 & 730 & 12.6 & 0.535 \\
\hline Surgery & 726 & 12.2 & 1424 & 23.9 & $<0.001$ \\
\hline Intensive care & 563 & 8.8 & 62 & 1.0 & $<0.001$ \\
\hline Paediatrics & 12 & 0.2 & 209 & 3.4 & $<0.001$ \\
\hline Internal medicine & 1755 & 29.7 & 899 & 15.1 & $<0.001$ \\
\hline Orthopaedics & 103 & 1.7 & 651 & 11.3 & $<0.001$ \\
\hline Neurology & 706 & 11.9 & 430 & 7.3 & $<0.001$ \\
\hline Lung disease & 779 & 13.2 & 384 & 6.5 & $<0.001$ \\
\hline Ear, nose and throat & 26 & 0.4 & 264 & 4.3 & $<0.001$ \\
\hline Urology & 68 & 1.1 & 280 & 4.7 & $<0.001$ \\
\hline Otherł & 535 & 8.5 & 626 & 9.9 & 0.04 \\
\hline Patient admitted to surgical department & 1003 & 16.5 & 2976 & 49.7 & $<0.001$ \\
\hline
\end{tabular}

${ }^{*}$ For patient characteristics unweighted numbers are given, \% are weighted for hospital type. †Hospital type rates are corrected for the stratified sample.

‡Other: all other departments $<3.5 \%$, for example geriatrics, gynaecology, ophthalmology. 


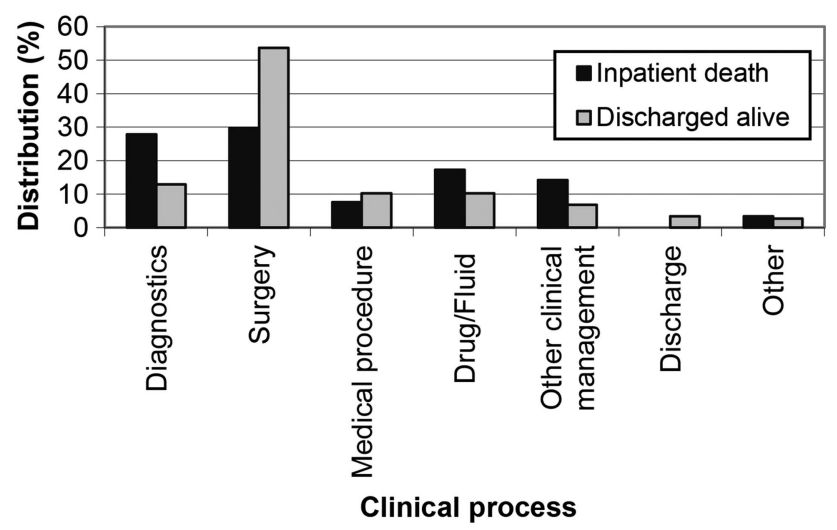

Figure 1 Distribution of clinical process related to preventable adverse event; \% are weighted for hospital type.

more surgical site infections, nerve injuries after surgery and failed surgical procedures were found during admission.

Second, as was the case with the clinical process related to the AEs, it appears that the distribution between the groups seems to vary. For the main categories, as a proportion of all AEs, a lower proportion of surgical AEs and a higher proportion of preventable hospital-acquired infections are found in the population of inpatient deaths in comparison with patients discharged alive (table 3). This again is related to differences in departments to which the patient was admitted between the two groups.

There are a number of preventable $\mathrm{AE}$ types that occur rarely in patients discharged alive and are found in inpatient deaths, for example, aspiration or sepsis/ bacteraemia.

\section{DISCUSSION}

\section{Main findings}

Inpatient deaths differ in patient and admission characteristics from patients discharged alive. Patients who died in hospital are on average older, have had a longer length of stay and are more often urgently admitted. Additionally, the department to which the patient was admitted differs between the two groups; for inpatient deaths this is less often a surgical department such as general surgery, orthopaedics, or urology. The number of AEs and preventable AEs differ, occurring at least twice as often in inpatient deaths. There are also differences in distribution of the clinical processes related to the $\mathrm{AE}$ and type of AEs. Consistent with fewer admissions to a surgical department, preventable AEs in inpatient deaths were proportionally less often related to the surgical process. A few AEs occur rarely in patients discharged alive: sepsis/bacteraemia and aspiration, and this is most likely because these outcomes often lead to a patient's death. No specific type of preventable AE present in patients discharged alive was absent in deceased patients.
Implications for practice, policy and research

Patient record review used in large national AE studies, or in hospitals as a part of the quality and safety cycle, are often performed, but are also very costly projects. It is important to know if efficiency can be improved by exclusively sampling or oversampling inpatient deaths.

We found that exclusively sampling or oversampling inpatient deaths does seem to be an efficient method: fewer patient records need to be studied to identify where safety improvements are possible; especially when the goal is not specifically the estimation of incidences for the total hospital population, but primarily to obtain as much information as possible on patient safety threats and potential solutions, this seems to be an efficient choice as fewer patient records are required to find one preventable AE. This goal is most likely the case for individual hospitals performing chart review as part of their quality and safety improvement cycle. In this case, the results of a structured review of complete patient admissions provide information on improvement possibilities specific for that hospital. The results are often discussed in morbidity and mortality meetings, where additional information on the preventable AEs can be acquired from the involved physicians and nurses. This also may contribute to raising a shared sense of urgency and commitment to improvement. A focus on reviews of deaths is likely to promote interest in the measurement of preventable deaths and perhaps even differences between organisations. However, this will be a difficult undertaking given the large samples that are needed to do so and also the low prevalence of preventable deaths and the limited number of inhospital deaths.

Exclusively studying inpatient deaths may underexpose improvement possibilities, especially on wards where patients are proportionally less likely to die. So for some wards it would not suffice to only research hospital deaths. Moreover, through chart review, certain types of problems in healthcare will not be found. Other research has shown that different methods often produce complementary information on patient safety and often have little overlap. ${ }^{10-12}{ }^{16}$ Our results also show that types of preventable AEs in the hospitalised population are heterogeneous and spread across many different infrequently occurring specific types. So for one hospital alone it will not necessarily allow an understanding of patterns of harm, even when focusing on all hospital deaths.

For national studies estimating incidence rates of AEs and preventable AEs, reviewing only inpatient deaths will lead to valid information on the number of preventable deaths-these being the most severe kind of AEsbut not to valid information on incidence rates of preventable AEs for the total hospitalised population. This limits the usefulness to prioritise improvement possibilities, as assessing only inpatient deaths can lead to a biased view as to which domain is most important to target. On the other hand, omitting patient records of inpatient deaths in a study also does not seem to be a 
Table 3 Type of harm for all adverse event (AEs) and preventable AEs

\begin{tabular}{|c|c|c|c|c|}
\hline Type of harm & $\begin{array}{l}\text { Inpatient } \\
\text { death } A E, n\end{array}$ & $\begin{array}{l}\text { Inpatient death } \\
\text { Preventable AE, } n\end{array}$ & $\begin{array}{l}\text { Discharged } \\
\text { alive } A E, n\end{array}$ & $\begin{array}{l}\text { Discharged alive } \\
\text { Preventable AE, } n\end{array}$ \\
\hline Cardiovascular system, total (column \%)* & $96(11.2)$ & $41(11.3)$ & $20(5.3)$ & $5(3.4)$ \\
\hline Cardiac arrest & 6 & 1 & & \\
\hline Hypotension & 3 & 3 & 3 & 1 \\
\hline Hypertension & 1 & 1 & & \\
\hline Shock & 7 & 3 & & \\
\hline Arrhythmias or conduction abnormality & 9 & 4 & 4 & \\
\hline Myocardial ischemia & 15 & 7 & 4 & \\
\hline Heart failure & 32 & 13 & 4 & 2 \\
\hline Other cardiovascular event & 23 & 9 & 5 & 2 \\
\hline Respiratory system, total (column \%)* & $110(13.2)$ & $48(12.7)$ & $19(4.8)$ & $8(5.4)$ \\
\hline Pneumothorax & 24 & 3 & 5 & 1 \\
\hline Atelectasis & 1 & 1 & & \\
\hline Bronchospasm & & & 2 & \\
\hline Aspiration & 26 & 11 & 2 & \\
\hline Pulmonary embolus & 23 & 18 & 4 & 4 \\
\hline Other respiratory event & 36 & 15 & 6 & 3 \\
\hline Renal or endocrine system, total (column \%)* & $54(6.0)$ & $32(7.9)$ & $22(5.8)$ & $11(7.5)$ \\
\hline Fluid overload & 7 & 5 & 2 & 1 \\
\hline Dehydration or oliguria & 2 & 2 & 4 & 2 \\
\hline Hyperglycaemia & 1 & 1 & 3 & 2 \\
\hline Hypoglycaemia & 7 & 3 & 3 & 1 \\
\hline Hyperkalemia & 5 & 4 & & \\
\hline Renal insufficiency & 13 & 8 & 4 & 1 \\
\hline Other renal or endocrine event & 19 & 9 & 6 & 4 \\
\hline Haematological system, total (column \%)* & $56(6.2)$ & $26(6.6)$ & $19(5.5)$ & $7(6.1)$ \\
\hline Haemorrhage & 29 & 14 & 12 & 4 \\
\hline Thromboembolic venous event & 12 & 4 & 4 & 2 \\
\hline Haematoma & 4 & 2 & 3 & 1 \\
\hline Other haematological event & 11 & 6 & & \\
\hline Gastrointestinal system, total (column \%)* & $84(10.0)$ & $48(12.7)$ & $27(6.8)$ & $9(6.1)$ \\
\hline Nausea or vomiting & 1 & 1 & 4 & \\
\hline Diarrhoea & 2 & & 2 & \\
\hline Pancreatitis & & & 2 & \\
\hline lleus & 14 & 10 & 6 & 2 \\
\hline Intestinal tract bleeding & 21 & 7 & 3 & 1 \\
\hline Perforation & 17 & 11 & 3 & 2 \\
\hline Other gastrointestinal event & 29 & 19 & 7 & 4 \\
\hline Neurologic system, total (column \%)* & $52(6.0)$ & $25(6.3)$ & $4(4.5)$ & $11(7.5)$ \\
\hline Over sedation & & & 1 & \\
\hline Delirium or encephalopathy & 6 & 4 & 2 & 1 \\
\hline Seizure & 1 & & 1 & 1 \\
\hline Stroke or intracerebral haemorrhage & 30 & 11 & 4 & 2 \\
\hline Withdrawal symptoms & 3 & 3 & & \\
\hline Other neurologic event & 12 & 7 & 10 & 7 \\
\hline Hospital-acquired infection, total (column \%)* & $186(21.7)$ & $58(16.1)$ & $73(17.8)$ & $6(4.8)$ \\
\hline Catheter-related bloodstream infection & 19 & 3 & 3 & 1 \\
\hline Sepsis or bacteraemia unrelated to catheter & 88 & 34 & 5 & \\
\hline Ventilator-associated pneumonia & 3 & 1 & & \\
\hline Nosocomial pneumonia, not ventilator-related & 17 & 6 & 7 & 1 \\
\hline Urinary tract infection & 13 & 4 & 12 & 1 \\
\hline Surgical-site infection & 11 & 2 & 21 & 2 \\
\hline Clostridium difficile colitis & 2 & & 1 & \\
\hline Phlebitis & 2 & & & \\
\hline Infected foreign material & 7 & 4 & 11 & \\
\hline Other hospital-acquired infection & 24 & 4 & 13 & 1 \\
\hline Surgical event, total (column \%)* & $151(18.1)$ & $62(16.9)$ & $142(34.8)$ & $62(41.5)$ \\
\hline Postoperative haemorrhage & 48 & 18 & 30 & 9 \\
\hline
\end{tabular}




\begin{tabular}{|c|c|c|c|c|}
\hline Type of harm & $\begin{array}{l}\text { Inpatient } \\
\text { death } A E, n\end{array}$ & $\begin{array}{l}\text { Inpatient death } \\
\text { Preventable AE, n }\end{array}$ & $\begin{array}{l}\text { Discharged } \\
\text { alive } A E, n\end{array}$ & $\begin{array}{l}\text { Discharged alive } \\
\text { Preventable AE, } n\end{array}$ \\
\hline Postoperative haematoma & 3 & 1 & 6 & 2 \\
\hline Postoperative abscess & 5 & 2 & 7 & 1 \\
\hline Laceration or other organ injury & 14 & 4 & 11 & 7 \\
\hline $\begin{array}{l}\text { Unplanned removal of organ after intra-operative } \\
\text { injury }\end{array}$ & 6 & 3 & 3 & 1 \\
\hline Vascular injury & 3 & 1 & 1 & 1 \\
\hline Nerve injury & 1 & & 8 & 3 \\
\hline Wound dehiscence & 5 & 2 & 2 & 2 \\
\hline Anastomotic leakage & 16 & 7 & 5 & 1 \\
\hline Postoperative fistula & 2 & & 4 & 2 \\
\hline Failed procedure & 12 & 10 & 23 & 14 \\
\hline Unplanned return to surgery & 3 & 1 & 7 & 3 \\
\hline Other event & 33 & 13 & 35 & 16 \\
\hline Other types of harm, total (column \%)* & $66(7.7)$ & $35(9.5)$ & $61(14.8)$ & $27(17.7)$ \\
\hline Fever & 9 & 2 & 8 & \\
\hline Allergic reaction & 2 & & 5 & \\
\hline Pressure ulcer & 9 & 3 & 5 & 1 \\
\hline Rash & 8 & 3 & 6 & 1 \\
\hline Catheter complication & 3 & & & \\
\hline Fracture & 5 & 2 & 7 & 4 \\
\hline Other type of harm & 30 & 25 & 30 & 21 \\
\hline Total & $855(100)$ & $375(100)$ & $401(100)$ & $146(100)$ \\
\hline
\end{tabular}

${ }^{\star}$ For types of harm, unweighted numbers are given, for the main groups, $\%$ are weighted for hospital type.

good idea, as specific types of severe AEs will be overlooked, for example, sepsis-bacteraemia or aspiration. Given that the incidence of hospital deaths in most hospitals is around $5 \%$, some oversampling of this subgroup will be necessary in most studies.

\section{Strengths and limitations}

To our knowledge no previous study has compared inpatient deaths and hospital admissions discharged alive. The strength of our study is the large representative sample of nearly 12000 patient admissions, consisting of $50 \%$ inpatient deaths and $50 \%$ patient admissions discharged alive, reviewed in the same years by the same reviewers, thus making it an ideal sample for our research question.

Limitations of this study can be seen in the standard limitations of retrospective patient record review studies. First, information bias could occur in retrospective patient record review. It is likely that not all information on AEs and preventable AEs has been written down in the patient record. We do think that this form of bias is probably the same for the inpatient deaths as well as for patients discharged alive, since during treatment care providers do not know whether the patient will die. As has been recorded in other studies-and is also the case for our own study-retrospective patient record review of AEs is subject to moderate reliability. ${ }^{9}{ }^{17-19}$ Lastly, hindsight bias is often mentioned as another problem. ${ }^{8}{ }^{20}$ Hindsight bias is the influence of knowing the outcome and its severity on the judgement of causation and preventability. ${ }^{8} 2122$ The outcome in inpatient deaths is death and this is more severe than the outcome in the group of patients admitted alive, which is prolongation of hospital stay, temporary or permanent disability. Thus, hindsight bias may be a more serious problem in the sample of inpatient deaths and therefore, may have led to an overestimation of the number of preventable AEs and AEs contributing to the death of a patient (preventable death) in this subgroup. In our study, however, we do not expect the hindsight bias to be of a large influence on the distribution of the types of preventable AEs. This bias can only be fully prevented if the reviewers are blinded for the outcome; this, however, is not possible in large scale retrospective patient record review studies.

In conclusion, studying inpatient deaths with patient record review seems an efficient way to identify preventable AEs in comparison with patients discharged alive: we found more than double the results in the same number of patient records. To acquire information on as many improvement possibilities as possible, this would seem to be an efficient choice. However, when only studying inpatient deaths, awareness of the fact that some problems remain underexposed or unexposed is important. Besides, on certain hospital wards patients rarely die; thus for these wards it would not suffice to only research hospital deaths. When using the results to prioritise where improvement of patient safety is needed, one has to take into account these variations in distribution. 
Acknowledgements The authors would like to thank everyone who contributed to the study, especially the nurses and doctors who reviewed the patient records, and the 33 hospitals participating in the study, including their staff who facilitated the patient records.

Contributors RJB was involved in the analysis and interpretation of data, drafting of the article; MCdB, ML were involved in the design, interpretation of data, critical revision of its intellectual content; $\mathrm{CW}$ was involved in the design, critical revision of its intellectual content, guarantor. All authors approved the final version.

Funding Financial support for the study was received from the Dutch Ministry of Health, Welfare and Sport. Grant number: 314439.

Competing interests None declared.

Ethics approval The study protocol was reviewed and approved by the scientific committee of the EMGO+ Institute, and by the ethical review board of the VU University Medical Center.

Provenance and peer review Not commissioned; externally peer reviewed.

Data sharing statement No additional data are available.

Open Access This is an Open Access article distributed in accordance with the Creative Commons Attribution Non Commercial (CC BY-NC 4.0) license, which permits others to distribute, remix, adapt, build upon this work noncommercially, and license their derivative works on different terms, provided the original work is properly cited and the use is non-commercial. See: http:// creativecommons.org/licenses/by-nc/4.0/

\section{REFERENCES}

1. Leape LL, Brennan TA, Laird N, et al. The nature of adverse events in hospitalized patients. Results of the Harvard Medical Practice Study II. N Engl J Med 1991;324:377-84.

2. Zegers $M$, de Bruijne MC, Wagner $C$, et al. Adverse events and potentially preventable deaths in Dutch hospitals: results of a retrospective patient record review study. Qual Saf Health Care 2009;18:297-302.

3. Baker GR, Norton PG, Flintoft V, et al. The Canadian Adverse Events Study: the incidence of adverse events among hospital patients in Canada. CMAJ 2004;170:1678-86.

4. Vincent C, Neale G, Woloshynowych M. Adverse events in British hospitals: preliminary retrospective record review. BMJ 2001;322:517-19.

5. Davis P, Lay-Yee R, Briant R, et al. Adverse events in New Zealand public hospitals I: occurrence and impact. N Z Med J 2002;115:U271.
6. Hogan H, Healey F, Neale G, et al. Preventable deaths due to problems in care in English acute hospitals: a retrospective case record review study. BMJ Qual Saf 2012;21:737-45.

7. Briant R, Buchanan J, Lay-Yee R, et al. Representative case series from New Zealand public hospital admissions in 1998-III: adverse events and death. N Z Med J 2006;119:U1909.

8. Hayward RA, Hofer TP. Estimating hospital deaths due to medical errors: preventability is in the eye of the reviewer. JAMA 2001;286:415-20.

9. Baines RJ, Langelaan M, de Bruijne $\mathrm{MC}$, et al. Changes in adverse event rates in hospitals over time: a longitudinal retrospective patient record review study. BMJ Qual Saf 2013;22:290-8.

10. Christiaans-Dingelhoff I, Smits M, Zwaan L, et al. To what extent are adverse events found in patient records reported by patients and healthcare professionals via complaints, claims and incident reports? BMC Health Serv Res 2011;11:49.

11. Levtzion-Korach $\mathrm{O}$, Frankel $\mathrm{A}$, Alcalai $\mathrm{H}$, et al. Integrating incident data from five reporting systems to assess patient safety: making sense of the elephant. Jt Comm J Qual Patient Saf 2010;36:402-10.

12. Naessens JM, Campbell CR, Huddleston JM, et al. A comparison of hospital adverse events identified by three widely used detection methods. Int J Qual Health Care 2009;21:301-7.

13. Shojania KG, Thomas EJ. Trends in adverse events over time: why are we not improving? BMJ Qual Saf 2013;22:273-7.

14. Zegers $M$, de Bruijne $M C$, Wagner $C$, et al. Design of a retrospective patient record study on the occurrence of adverse events among patients in Dutch hospitals. BMC Health Serv Res 2007;7:27.

15. Landrigan $\mathrm{CP}$, Parry GJ, Bones $\mathrm{CB}$, et al. Temporal trends in rates of patient harm resulting from medical care. $N$ Engl J Med 2010;363:2124-34.

16. Michel P, Quenon JL, de Sarasqueta AM, et al. Comparison of three methods for estimating rates of adverse events and rates of preventable adverse events in acute care hospitals. BMJ 2004;328:199.

17. Zegers $\mathrm{M}$, de Bruijne $\mathrm{MC}$, Wagner $\mathrm{C}$, et al. The inter-rater agreement of retrospective assessments of adverse events does not improve with two reviewers per patient record. J Clin Epidemiol 2010;63:94-102.

18. Thomas EJ, Lipsitz SR, Studdert DM, et al. The reliability of medical record review for estimating adverse event rates. Ann Intern Med 2002;136:812-16.

19. Localio AR, Weaver SL, Landis JR, et al. Identifying adverse events caused by medical care: degree of physician agreement in a retrospective chart review. Ann Intern Med 1996;125:457-64.

20. Lilford R, Edwards A, Girling A, et al. Inter-rater reliability of case-note audit: a systematic review. J Health Serv Res Policy 2007;12:173-80.

21. Henriksen K, Kaplan H. Hindsight bias, outcome knowledge and adaptive learning. Qual Saf Health Care 2003;12(Suppl 2):ii46-50.

22. Fischhoff B. Hindsight not equal to foresight: the effect of outcome knowledge on judgment under uncertainty. 1975. Qual Saf Health Care 2003;12:304-11. 